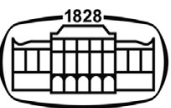

AKADÉMIAI KIADÓ

Journal of Psychedelic Studies

5 (2021) 3, 156-165

DOI:

$10.1556 / 2054.2021 .00187$

(c) 2021 The Author(s)

ORIGINAL RESEARCH PAPER

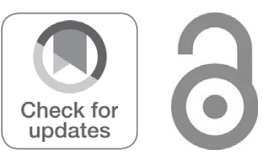

\section{A Semantic Scale Network analysis of the revised Mystical Experiences Questionnaire: A call for collaboration}

\author{
MITCH EARLEYWINE ${ }^{1}$, FIONA LOW ${ }^{1 *} \odot$ and JOSEPH DE LEO $^{2}$ \\ ${ }^{1}$ Department of Psychology, University at Albany, State University of New York, USA \\ ${ }^{2}$ Centre for Compassionate Care, Hamilton, Ontario, Canada
}

Received: July 2, 2021 • Revised manuscript received: October 18, 2021 - Accepted: October 18, 2021

Published online: November 16, 2021

\begin{abstract}
Background and aims: Multiple laboratories have proposed measures of subjective effects of psychedelics as potential mediators of their therapeutic impact. Other work has identified individual differences that covary with subjective responses in informative ways. The range of potential measures of responses, traits, and outcomes is vast. Ideas for new measures are likely numerous. The field will progress efficiently if proposed new scales can add incremental validity. Semantic Scale Network analyses identify conceptual overlap among scales based on items (rather than participant ratings), which could help laboratories avoid putting effort into measures that are unlikely to account for unique variance. Semantic Scale Network analyses can also reveal links to constructs from disparate research literatures, potentially helping investigators generate novel hypotheses and explain connections among disparate findings. The results of Semantic Scale Network analyses have the potential to improve as more investigators enter their scales into the corpus. Method: Example analyses using the revised Mystical Experiences Questionnaire (MEQ) underscore the uniqueness and discriminant validity of the MEQ subscales. Results: Findings dovetail with published theorizing and suggest potentially novel links with different therapeutic effects. The MEQ total or subscales overlap with measures of awe, inspiration, regret, dissatisfaction, transcendence, depression, fatigue, and spirituality. Links with measures of stress, alexithymia, and gender identity suggest lines of further work. Conclusions: This analytic approach might suggest unique applications for psychedelic-assisted treatments and provide perspectives on phenomena outside the field. As psychedelic researchers enter their scales to the corpus for Semantic Scale Network analyses, the field will benefit.
\end{abstract}

\section{KEYWORDS}

Semantic Scale Network, psychedelics, hallucinogens, Mystical Experiences Questionnaire, mystical experiences

\section{INTRODUCTION}

Numerous self-report measures address psychedelic use, subjective effects, predictors of these effects, associated outcomes, and potential mechanisms of therapeutic impact. The field could benefit from knowledge about the validity of these self-report scales. For example, subjective reactions to psychedelics covary with outcomes in psychedelic-assisted therapeutic experiences. As ratings of mystical, non-ordinary aspects of consciousness change, so do measures of psychopathology or wellbeing (See Luoma, Chwyl, Bathje, Davis, \& Lancelotta, 2020 for a review.). Trials show that increased mystical reactions precede improvements in multiple conditions, including cancer-related psychological distress (Griffiths et al., 2016; Richards, Rhead, Dileo, Yensen, \& Kurland, 1977), depression (Carhart-Harris, Bolstridge et al., 2018), alcohol problems (Bogenschutz et al., 2015), and smoking cessation (Garcia-Romeu, Griffiths, \& Johnson, 2014). Surveys also support the idea, despite focusing on different psychedelics, recruitment, and measures (e.g., Agin-Liebes et al., 2021; Davis, Barrett, So, et al., 2021; Sarris et al., 2021). Related work on personality predictors of subjective responses
Washington Avenue SS 217, Albany, NY 12203, USA.

Tel.: +19178312994.

E-mail: flow@albany.edu 
suggests that certain traits covary with reactions to administration (Haijen et al., 2018; Smigielski et al., 2019). This line of research can reveal who might benefit most from psychedelic-assisted treatment.

As this research proliferates, investigators might examine which subjective effects are most important, and for whom, as they continue the quest for maximizing psychedelicassisted treatments. Recent work suggests that psychological insight (Davis, Barrett, Gukasyan, et al., 2021) and emotional breakthrough experiences (Roseman et al., 2019) account for unique variance in improvements above their associations with mystical experiences. The incremental validity of these measures reveals that gaining awareness into emotions or getting closure on affect-laden struggles during the acute effects of relevant molecules could improve wellbeing. These insights and breakthroughs overlap with mystical experiences but help account for improvements in wellbeing. But the choices among traits that might predict these responses are voluminous; measures of wellbeing and symptoms are legion. Deciding which measures to use can challenge any laboratory and a lack of convergence across laboratories can leave the field fragmented.

Researchers might hypothesize that other aspects of subjective effects could play a role in psychedelic-assisted treatment for subsamples of participants. Gathering the relevant data to support the incremental validity of each construct is no easy feat. Appropriate sample sizes and sampling strategies are expensive. Correlations are unstable below samples of 250 (Schönbrodt \& Perugini, 2013). Selfselected samples willing to volunteer might not generalize to the population, potentially requiring paid participants. In addition, even devoted experts might be unaware of every relevant scale across psychology, psychiatry, and health. Initial Semantic Scale Network analyses (Rosenbusch, Wanders, \& Pit, 2020), which examine the content of the questions (rather than people's responses to them), could save researchers effort, helping to maximize resources. These analyses will improve as more investigators contribute their scales to the corpus, too.

\section{Semantic scale network analyses}

Semantic networks represent information as a pattern of interconnected words or expressions. Typically, each word or expression is represented by a node and distances between nodes reflect how closely they might associate based on lexical, cognitive, or semantic similarity (Quillian, 1963). Investigators in computational social sciences formed a network of scales (rather than words or expressions) to help assess similarity (Rosenbusch et al., 2020). They amassed a corpus of over 4,000 published scales. They programmed search strategies to allow others to see if proposed new scales are similar to those already published. The program utilizes simple word matching and also considers words with similar meanings. The analyses identify overlapping topics in scales from disparate literatures.

The computation of these measures appears in detail elsewhere (Rosenbusch et al., 2020), but rests on word similarity, word importance, and latent semantic analysis. Word similarity is based on the number of words that overlap in two items relative to the square root of the product of the lengths of the items. Two items with no overlap have a word similarity score of 0 ; complete overlap leads to a similarity score of 1 . Partial overlap leads to scores between 0 and 1. By taking into account the length of each item, longer items do not receive higher similarity scores simply because they contain more words. Two items that are four words long each and share 3 words receive a similarity score of $0.75\left(3 / \mathrm{SQRT}\left(4^{*} 4\right)\right)$.

The word similarity score is then weighted by word importance, which rests on its infrequency in the total corpus of scales. Rarer words are more important than those that appear in nearly every scale. Importance scores are the logarithm of a ratio that reflects the word's rarity (the total number of scales in the corpus divided by the number of scales that contain the word). Importance $=\log$ (total scales/scales with target word). Thus, sharing a common word like "think" does not increase scores as much as sharing a rare word like "mystical."

The program then adds to the score based on latent semantic analysis, which assesses similarity beyond word matching. Words that do not match (e.g., "snow" and "ice") can still be similar given how often they co-occur with the same words (e.g., "cold"). Two words that frequently appear with the same other words essentially share a latent topic, suggesting similarity and increasing the similarity score. Certain latent topics co-occur more than others, reflecting another form of similarity, which also increases the similarity measure. Matrices formed from these co-occurrence scores are reduced to provide a single score. Scores increase when scales share matching, important, words as well as words from the same topics. Researchers can enter the same scale at any time to replicate the discovery of overlapping scales.

The final analysis program computes vectors of distances between shared meanings across scales. These measures form a matrix to reveal an extent of the overlap (from -1 for maximal dissimilarity to +1 for maximal similarity). Current corpus statistics range from -0.66 (implying very little overlap compared to other scales) to 1.0 (implying the most overlap as any in the corpus). Descriptive statistics aid interpretation of results. The authors caution against arbitrary cut-offs but note that the current average score across the entire corpus is 0.007 with a median of 0.001 and standard deviation of 0.076 . An analysis of closest neighbors (each scale and its most similar neighbour) in the network reveals an average rating of 0.68 with a median of 0.674 and a standard deviation of 0.164 . These statistics might change as more scales enter the corpus.

The Semantic Scale Network analysis can estimate overlap with available scales prior to any data collection, potentially saving researchers considerable time and effort. Unlike common empirical approaches, the analysis allows for the entry of individual items that the program compares to available scales based on shared vocabulary and comparable meaning. This computerized look at semantic 
similarity, word matching, and shared conceptual content can also reveal if some subscales might overlap with key correlates of a targeted treatment. For example, to focus on outcomes for psychedelic-assisted treatment, one subscale might overlap with a measure of trauma; another might overlap more with symptoms of depression. The application program is quite intuitive. Interested parties can preprocess scale questions by removing words like "the," "and," or "to" and submitting them for analysis here: https://rosenbusch. shinyapps.io/semantic_net/. Researchers can add to the corpus easily as well, at this link: https://nlpsych.eu.qualtrics. com/jfe/form/SV_6sdqzxEVd7EP3Rb. Adding new scales can help investigators examine overlap among current measures and assist the generation of new ones.

For example, investigators might believe that a psychedelic-induced change in a subjective sense of "togetherness" might account for unique variance in outcomes. Investigators might generate potential items, ask for feedback from relevant experts, and form a "Psychedelic-Induced Sense of Togetherness Questionnaire" (see Gehlbach \& Artino, 2018). But before the group spends time, money, and effort establishing psychometric properties, symptom-specific impact, and incremental validity, they might test the items against the corpus of available scales. The Semantic Network analysis of the lone item, "I felt a sense of togetherness" overlaps with a measure of awe and one index of freedom. Adding "I felt close to my friends and family" to this proposed Togetherness Scale reveals overlap with indices of attachment and friendliness. These results might inform the research group's efforts. The analysis might reveal an established inventory that seems appropriate. Alternatively, the results could help them focus the new items to help ensure discriminant validity. In addition, the overlap might support the idea that changes in this new subjective sense of togetherness could mediate psychedelicassisted therapy's impact on social support or vary with group (rather than individual) administration.

In addition to avoiding redundancies, semantic network analyses can reveal unexpected connections among scales (Burk, Chappell, Gregory, Joslyn, \& McGrath, 2012). Comparable networks underly the creation of innovative products; unexpected results can inspire new, practical hypotheses (Li, Kenett, Hu, \& Beaty, 2021). Surprising results from measures of overlap could help researchers generate original hypotheses consistent with relevant theories. Returning to the hypothetical "togetherness" scale, Semantic Scale Network analysis reveals overlap with an inventory related to "commitment to a service provider." This disparate link might inspire the research group to craft items related to a sense of togetherness with the guides or therapists in the psychedelic-assisted treatment- an approach that has shown potential in research on smoking cessation (Noorani, Garcia-Romeu, Swift, Griffiths, \& Johnson, 2018). (Hindsight bias would make this idea seem self-evident, but other measures of "connectedness" rarely address specific relationships this way (Forstmann, Yudkin, Prosser, Heller, \& Crockett, 2020), suggesting that this focus might show incremental validity.)
But hypotheticals are no substitute for data. To provide a feel for the information these Semantic Scale Network analyses could provide, we analyzed the Revised Mystical Experiences Questionnaire (MEQ; Barrett, Johnson, \& Griffiths, 2015) as an example. We had hoped to identify scales that overlap with the full scale and subscales, which might reveal their novelty or inform the generation of improvements. In addition, we were eager to see if unexpected links might suggest fruitful lines for future work.

\section{Analyses}

The MEQ, a widely cited index of subjective responses to psychedelics, draws on philosophies of ineffable moments as described in ancient and classical writings (Stace, 1960). Decades of empirical work focused on identifying facets of these experiences that follow the administration of psychedelics, which inspired the latest versions of the scale (Griffiths, Richards, McCann, \& Jesse, 2006; MacLean, Leoutsakos, Johnson, \& Griffiths, 2012; Pahnke, 1969). The 30-item revised MEQ includes four subscales based on responses to controlled, therapeutic administration of psilocybin: positive mood, ineffability, mystical experiences, and transcendence of space and time. Although sample sizes do not always approach the idealized recommendations of statisticians (MacCallum, Widaman, Zhang, \& Hong, 1999), this four-factor solution appeared in previous work on a longer form of the scale (MacLean et al., 2012), and showed invariance in a Portuguese translation (Schenberg, Tofoli, Rezinovsky, \& Silveira, 2017). Psychometric properties are consistently acceptable, with internal consistencies above 0.80 . Total and factor scores covary with relevant constructs, including ratings of how meaningful and spiritually significant the psilocybin experience seemed (Barrett et al., 2015). Total scores also increase for those who set clear intentions when they take psychedelics in naturalistic settings (Haijen et al., 2018). The Semantic Scale Network analyses required submitting items to the program mentioned above.

\section{RESULTS AND DISCUSSION}

We focused on finding five nearest neighbors for illustrative purposes, but investigators can see up to 15 measurement devices with the highest overlap. For those interested in a more thorough network, each of the neighboring scales can connect to up to 15 more measures. Figures $1-5$ reveal the networks for the total scale and each subscale. Table 1 lists the 5 most overlapping scales for each. Details and discussion appear below.

\section{Total scale}

The total scale showed overlap scores ranging from 0.80 to 0.84 . The five most overlapping scales include an index of inspiration as well as multiple measures from industrial and organizational research that are likely unfamiliar to most researchers who study psychoactive drugs. The inspiration scale focuses on the depth and frequency of feeling inspired. 


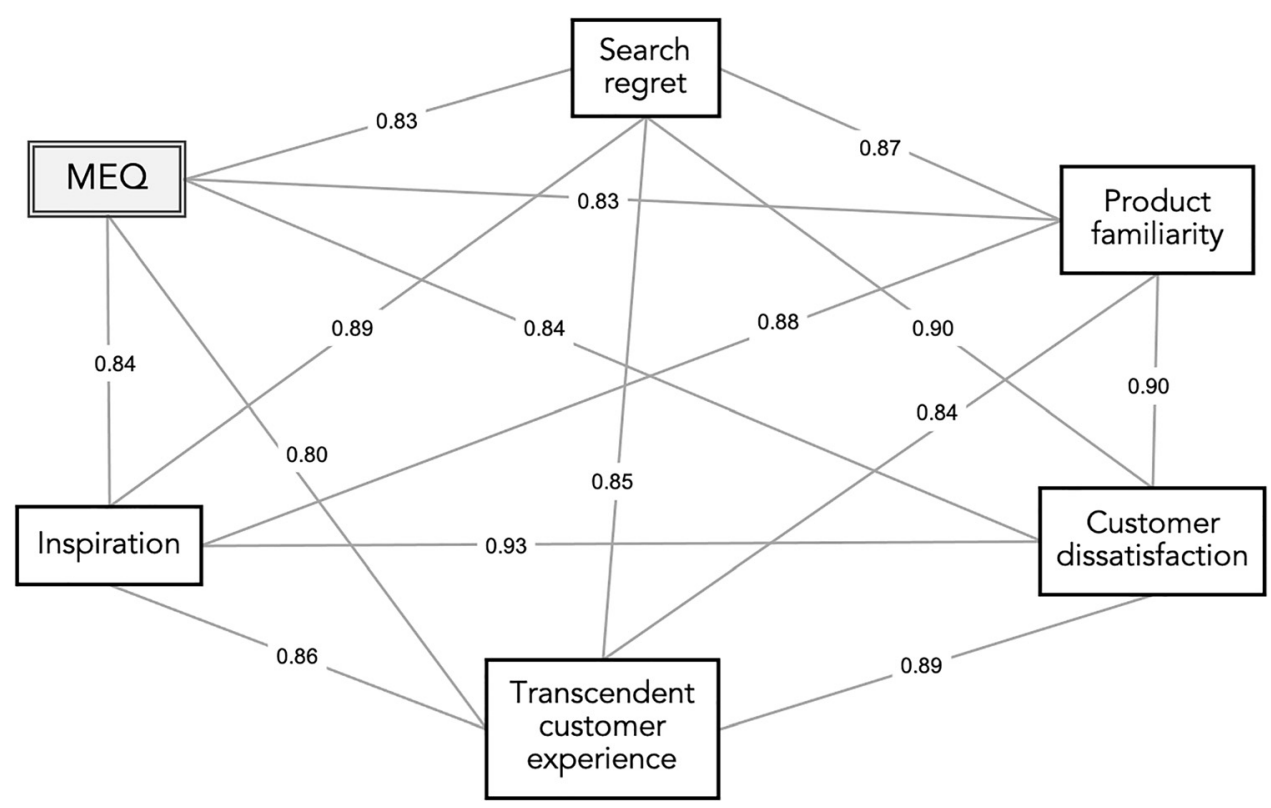

Fig. 1. Network for the MEQ total scale

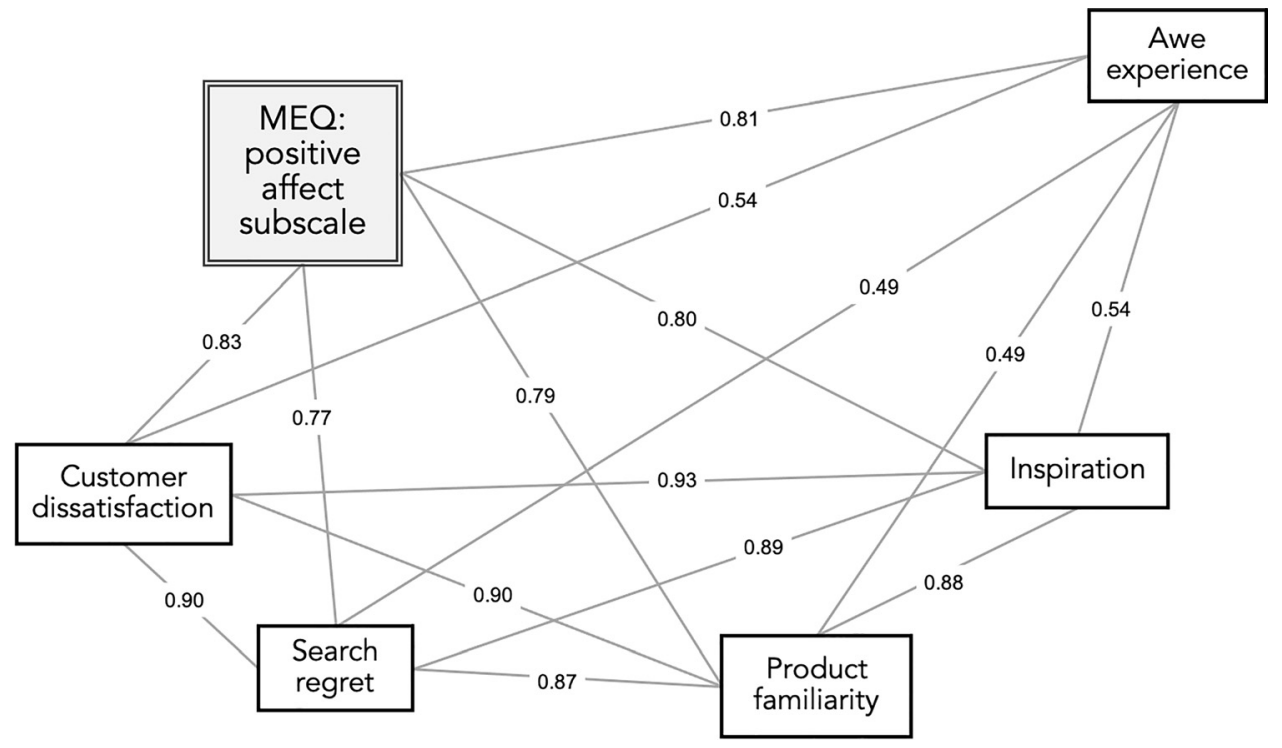

Fig. 2. Network for the MEQ positive affect subscale

Scores covary with intrinsic motivation as well as the number of patents held in a sample of patent-holders (Thrash \& Elliot, 2003). This overlap might relate to links between psychedelics and creativity (Girn, Mills, Roseman, Carhart-Harris, \& Christoff, 2020; Mason et al., 2021). The role of inspiration in associations between psychedelics and creativity has received little attention. Most research has focused on how the experience leads to divergent thinking rather than the motivation to create unique works. Research on the role of psychedelics for increasing inspiration and the generation of creative work might reveal inspiration's role as a mechanism underlying any links between psychedelics and creativity.
The overlap with consumer experiences is best interpreted while considering all the relevant overlapping constructs. The program identified overlap with a "transcendent customer experience" scale that focused on how attendance at an event devoted to a product (a car) could create intense, emotional, engaging experiences that could alter a person's sense of self, knowledge, and ideals (Schouten, McAlexander, \& Koenig, 2007). A measure of customer dissatisfaction also received a high overlap score (Bougie, Pieters, \& Zeelenberg, 2003). This dissatisfaction scale focuses on how displeased consumers felt after customer experiences. An index of product familiarity that focuses on how foreign, unknown, or novel a product appears (Machleit, Allen, \& 


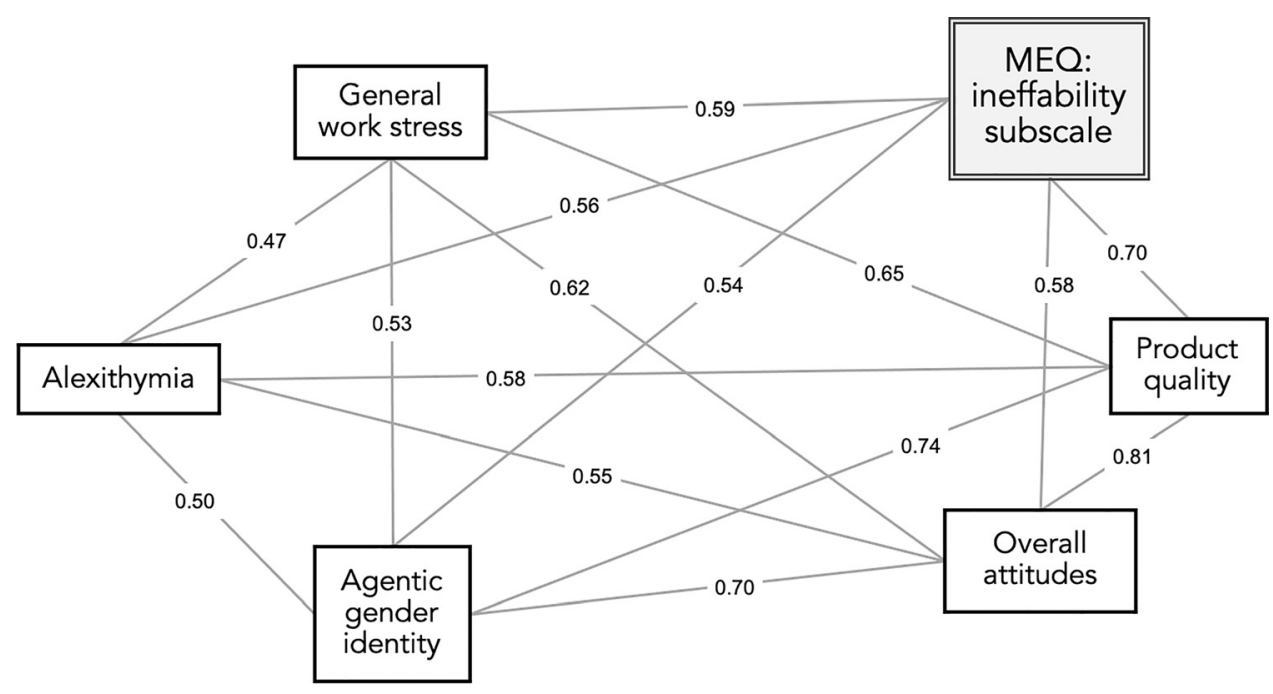

Fig. 3. Network for the MEQ ineffable subscale

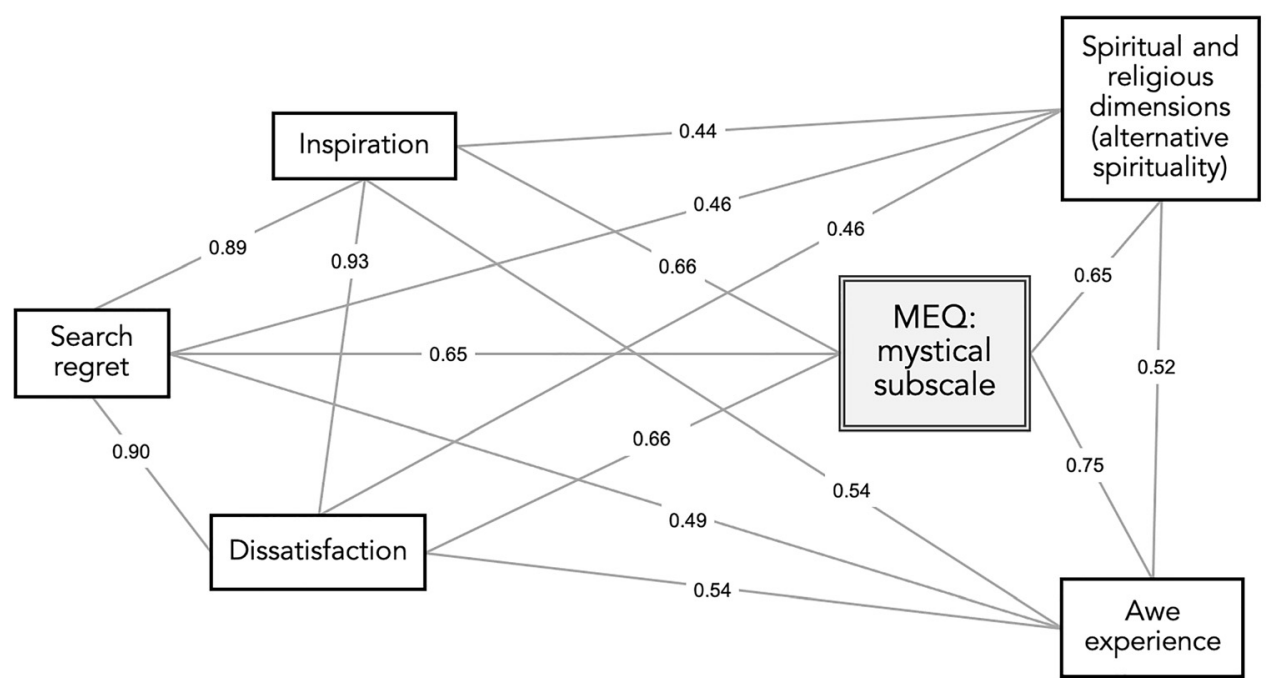

Fig. 4. Network for the MEQ mystical subscale

Madden, 1993) also overlapped, echoing MEQ items that emphasize the inordinate and indescribable nature of subjective responses to psychedelics. In addition, a measure of "search regret," which focuses on negative affect and attributions associated with an unsuccessful hunt for a desired product, showed considerable overlap (Reynolds, Folse, \& Jones, 2006).

The overlap with aspects of a quest for (or reaction to) a consumer product could imply that marketers work to meet needs comparable to those inherent in the mystical experience. Advertisements frequently promise hedonic and utilitarian improvements that might parallel the affect, focus, and certainty addressed in the MEQ. Researchers in product development focus on communicating tangible and abstract advantages of objects or services to potential consumers, an approach dubbed "value proposition design" (da Costa Fernandes, Pigosso, McAloone, \& Rozenfeld, 2020; Kyhnau $\&$ Nielsen, 2015). Recent work reveals a related link between lifetime psychedelic use and connection to nature, a finding that inspired a hypothesis that the molecules might decrease consumerism (Kettner, Gandy, Haijen, \& Carhart-Harris, 2019).

\section{Positive affect subscale}

The Positive Affect Subscale of the MEQ overlapped with four of the instruments identified in the analysis of the Total Scale (search regret, customer dissatisfaction, product familiarity, and inspiration). Instead of the transcendent customer experience, positive affect overlapped with a new measure of awe (Yaden et al., 2019). Awe might serve as the mechanism underlying the therapeutic effect of psychedelics (Hendricks, 2018). This awe scale includes six factors: time compression, loss of sense of self, connectedness, vastness (experiencing the presence of something greater than oneself), need for accommodation (the sense that the experience 


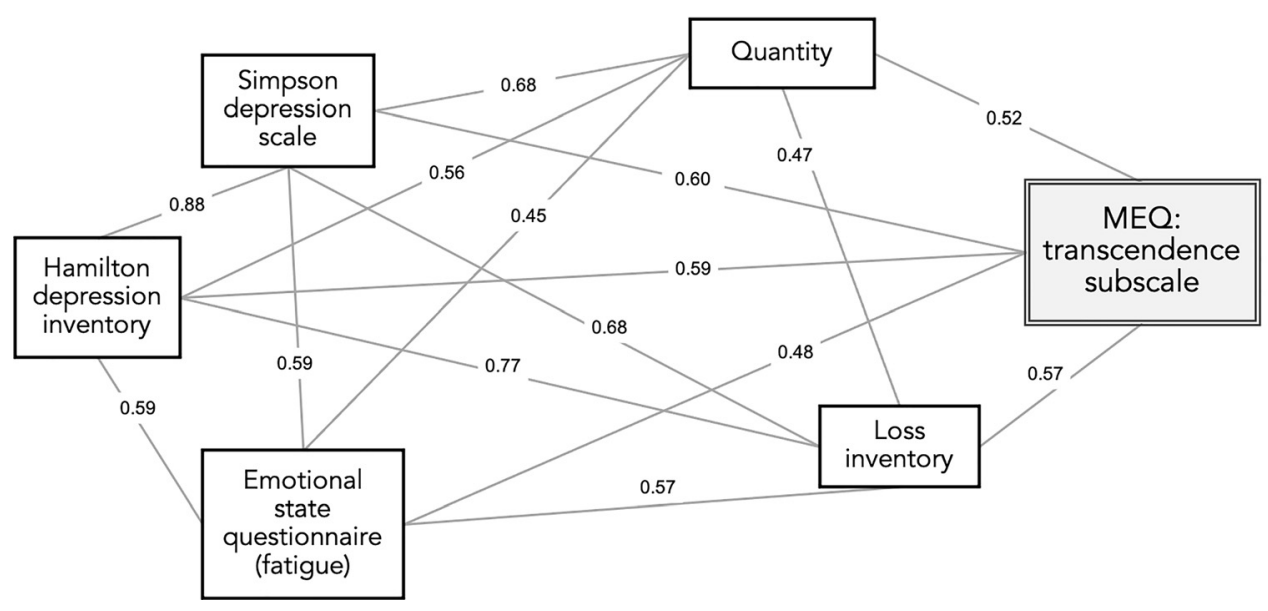

Fig. 5. Network for the MEQ transcendence of time and space subscale

Table 1. Overlaps with the total and four subscales of the MEQ

\begin{tabular}{|c|c|c|}
\hline MEQ & Related scales & Similarity \\
\hline \multirow[t]{5}{*}{ Total scale } & Inspiration & 0.84 \\
\hline & Customer dissatisfaction & 0.84 \\
\hline & Search regret & 0.83 \\
\hline & Product familiarity & 0.83 \\
\hline & $\begin{array}{l}\text { Transcendent customer } \\
\text { experience }\end{array}$ & 0.80 \\
\hline \multirow[t]{5}{*}{ Positive affect subscale } & Customer dissatisfaction & 0.83 \\
\hline & Awe experience & 0.81 \\
\hline & Inspiration & 0.80 \\
\hline & Product familiarity & 0.79 \\
\hline & Search regret & 0.77 \\
\hline \multirow[t]{5}{*}{ Ineffable subscale } & Product quality & 0.70 \\
\hline & General work stress & 0.59 \\
\hline & Overall attitudes & 0.58 \\
\hline & Alexithymia & 0.56 \\
\hline & Agentic gender identity & 0.54 \\
\hline \multirow[t]{5}{*}{ Mystical subscale } & Awe experience & 0.75 \\
\hline & Inspiration & 0.66 \\
\hline & Dissatisfaction & 0.66 \\
\hline & Search regret & 0.65 \\
\hline & $\begin{array}{c}\text { Spiritual and religious } \\
\text { dimensions (alternative } \\
\text { spirituality) }\end{array}$ & 0.65 \\
\hline \multirow{5}{*}{$\begin{array}{l}\text { Transcendence of time } \\
\text { and space subscale }\end{array}$} & Simpson depression scale & 0.60 \\
\hline & $\begin{array}{l}\text { Hamilton depression } \\
\text { inventory }\end{array}$ & 0.59 \\
\hline & Loss inventory & 0.57 \\
\hline & Quantity & 0.52 \\
\hline & $\begin{array}{c}\text { Emotional state } \\
\text { questionnaire (fatigue) }\end{array}$ & 0.48 \\
\hline
\end{tabular}

was difficult to comprehend, integrate, or process), and physiological signs (a dropped jaw, chills, goosebumps, widened eyes). The factors are comparable to scales employed in psychedelics research. The Challenging Experiences Questionnaire (Barrett et al., 2015) contains items addressing loss of sense of self, need for accommodation and physiological correlates. The Ego-Dissolution Inventory touches on loss of sense of self and vastness (Nour, Evans,
Nutt, \& Carhart-Harris, 2016). A call for a measure of connectedness appears in this literature (Carhart-Harris, Erritzoe, Haijen, Kaelen, \& Watts, 2018), which the connectedness subscale for this measure might provide. This awe experience scale (AWE-S) might serve as an intriguing measure of subjective effects in administration trials consistent with theories of how awe might underly therapeutic effects (Hendricks, 2018). Overlap scores ranged from 0.77 to 0.83 .

\section{Ineffability subscale}

The Ineffable Subscale overlapped with a measure of product quality that focuses on excellence (Quality of the Product, Absolute; Jo, 2007), as well as scales that assess alexithymia (Bagby, Parker, \& Taylor, 1994), agentic gender identity (Winterich, Mittal, \& Ross, 2009), attitudes about approaches to job interviews (van der Zee, Bakker, \& Bakker, 2002), and stress (Fuller et al., 2003). The assessment of the absolute quality of the product (Jo, 2007) likely overlaps because of similar ideas related to an excellence that might be beyond words. Alexithymia items suggested that difficulty describing one's emotional experience might parallel the difficulties inherent in describing the subjective effects of psychedelics (Barrett et al., 2015). The idea that psychedelic therapy might improve the ability to identify and articulate emotions has intuitive appeal given established links to emotional breakthroughs (Roseman et al., 2019) and emotional enhancements (Rifkin, Maraver, \& Colzato, 2020), though clinical work currently does not focus on this skill. Given established links among alexithymia, depression, and anxiety (Marchesi, Brusamonti, \& Maggini, 2000), this result echoes other calls for extending clinical trials to anxiety disorders (Muttoni, Ardissino, \& John, 2019).

The assessment of agentic gender identity focuses on socialized behaviors stereotypically described as feminine or masculine. (The authors describe communal approaches to interpersonal interactions that emphasize caring, harmony in relationships, and concern for the welfare of others as feminine while viewing concern for agency, self-assertion, and control as masculine.) The overlap with this subscale of 
the MEQ underscores previous work suggesting links between psychedelic use and liberal or communal attitudes (Nour, Evans, \& Carhart-Harris, 2017), connectedness (Carhart-Harris, Erritzoe, et al., 2018), as well as theories relating continued use of psychedelics to prosocial values (Griffiths et al., 2018; Roberts, 2013). Continued work focusing on how psychedelics might improve relationships and contribution to community while decreasing selffocused concerns about agency and self-assertion might prove heuristic.

The "overall attitudes" items address how pleasant, good, sensible, effective, professional, strong, and efficient an interview process seemed (van der Zee et al., 2002). The items appear comparable to MEQ items focusing on a dynamic, variable, interactive process with the potential to seem strong and pleasant. The overlap with a stress index supports recommendations for extending psychedelic treatments to those who do not qualify for standard diagnoses of psychopathology (Gandy, 2019), many of whom might appreciate anxiolytic effects. Overlap scores ranged from 0.54 to 0.70 .

\section{Mystical subscale}

Semantic Scale Network analysis of the Mystical Subscale overlapped with the same measures of awe, inspiration, search regret and dissatisfaction mentioned above. The scale also overlapped with the "Alternative Spirituality" factor of the Spiritual and Religious Dimensions Scale (Nasel \& Haynes, 2005). The items on this factor include experiences that are divine, mystical, and transcending time. Other items reflect a commitment to personal growth, meditation, and a willingness to turn to multiple texts from different religious traditions. This overlap is consistent with recent theorizing relating psychedelics to existential therapies (Sarikhani, 2019) and ideas for viewing psychedelics as only a single component in multi-faceted approaches to self-care (e.g., Griffiths et al., 2011; Rochester et al., 2021; Roberts, 2013). Assessments of how psychedelic use might vary with selfcare might be worth the effort, as emphasized in previous publications (Griffiths et al., 2018). Overlap scores ranged from 0.65 to 0.75 .

\section{Transcendence of time and space subscale}

This final subscale, which focuses on the loss of the usual sense of time and location, overlapped with multiple measures of depression and an assessment device used to evaluate how substantial, numerous, and extensive arguments appeared in advertisements (Raju, Unnava, \& Montgomery, 2009). The evaluations of the arguments overlap conceptually with how unusual the psychedelic experience seems. The depression measures include The Hamilton Depression Inventory (Reynolds \& Kobak, 1995), The Simpson Depression Scale (Simpson, Hackett, \& Kline, 1966), the fatigue subscale of the Emotional State Questionnaire (Aluoja, Shlik, Vasar, Luuk, \& Leinsalu, 1999), and the Loss Inventory, a measure of responses to disability (Niemeier, Kennedy, McKinley, \& Cifu, 2004). These might appear because of repetitions of the word "loss" on these MEQ items (loss of usual sense of time, space, and awareness). Substituting "unusual" for "loss of" led to a higher overlap with the measure of awe mentioned above and less overlap with depression scales. Nevertheless, the Hamilton has a history of use in psychedelic research, recently revealing improvements in clinical trials (Carhart-Harris et al., 2021; Davis, Barrett, May et al., 2021). The fatigue subscale of the Emotional State Questionnaire focuses on psychomotor slowing and difficulty concentrating. The Loss Inventory assesses both cognitive and emotional symptoms consistent with grief or depression. Clinical applications of psychedelics to grief sound promising but remain rare. Overlap scores ranged from 0.48 to 0.60 .

Given the overlap, researchers might examine if the transcendence of space and time subscale covaries with antidepressant effects more than other subscales. A study of acute responses to psilocybin found that items reflecting a comparable sense of oneness in space and time known as "Oceanic Boundlessness" correlated highly with subsequent antidepressant effects (Roseman, Nutt, \& Carhart-Harris, 2018). Cannabis users who expected a large dose would alter these items also expected more antidepressant effects from a cannabis-assisted treatment as well (Earleywine et al., 2021).

The frequency of somatic and emotional items raises questions about symptom-specific alterations as well. Psychedelics might improve some symptoms of depression more than others. (A sample of ayahuasca users, for example, reported that the psychoactive brew altered affective symptoms like hope, sad mood, and happiness more than other symptoms (Gilbert, Earleywine, Mian, \& Altman, 2021)). Perhaps psilocybin's impact on depression is mediated by alterations in perceptions of time and space, or this subjective effect uniquely impacts symptoms like fatigue and focus.

\section{CONCLUSIONS (AND A REQUEST)}

Semantic Scale Network analyses can reveal overlap among published scales and assist researchers eager to construct new measures. Analyses focus on an empirically derived network of texts from the items of over 4,000 questionnaires to provide a measure of overlap. The analyses can help prevent duplicating effort in the construction of assessment devices and identify common constructs that might underly indices of related phenomena. Given recent findings that suggest that subjective responses to psychedelics potentially mediate their therapeutic effects, that these effects might covary with personality, and that outcomes could include an array of symptoms or indices of wellbeing, theorists might be eager to fashion new measures (or at least examine overlap on the ones that they choose). The numerous available scales for assessing subjective responses, personality, and outcomes might leave researchers in a quandary as they select questionnaires to address these links. Before laboratories devote resources for gathering data from participants, an examination of semantic overlap could prove 
helpful. In addition, the corpus and approach could lend itself to modularity maximization approaches to identify the emergence of modules of tightly interconnected scales without requiring expensive data-collection from hundreds of participants.

An example Semantic Scale Network analysis for the Revised Mystical Experiences Questionnaire (MEQ) confirmed some of the scale's novelty and convergent validity while revealing unanticipated links with constructs from outside of research on psychoactive drugs. Results also supported ideas for examining subscale-specific links with subsets of depressive symptoms and grief, as well as associations with consumerism, alexithymia, relationships, self-care, and awe. The overlap suggested that forming a new measure of psychedelic-induced awe might be unnecessary; a recent one might tap relevant factors (Yaden et al., 2019). The same measure of awe also includes physical signs that might make useful additions to measures of subjective responses, including physiological signs like a dropped jaw, chills, goosebumps, widened eyes.

Readers familiar with this literature will note a distinct absence of reported overlap with other established measures of subjective effects of psychedelics. Classic measures of subjective responses to psychoactive substances and nonordinary states are noticeably missing. At the time these analyses were performed, the Altered States of Consciousness Rating Scale (Dittrich, 1998), States of Consciousness Questionnaire (Pahnke, 1966), and Hallucinogen Rating Scale (Strassman, Qualls, Uhlenhuth, \& Kellner, 1994) had not been entered into the corpus. A list of other important reactions to psychedelics, personality traits, and indices of functioning could be extensive. Adding these to the corpus might help laboratories make important decisions about which constructs to assess and how.

We would like to conclude with a request for authors to submit relevant scales to the corpus. Adding the items could help prevent a proliferation of overlapping scales that might offer little incremental validity, and the results from Semantic Scale Network analyses might inspire creative ideas about new hypotheses. Those who hypothesize about new constructs relevant to subjective effects, (or traits that might predict reactions to psychedelic-assisted treatments, or domains of wellbeing that these molecules might alter), could benefit from this analytic approach prior to collecting any data. In addition, entering new scales into the corpus can help the community of psychedelic researchers make the most of limited resources, potentially improving the trajectory for these lines of research.

\section{REFERENCES}

Agin-Liebes, G., Haas, T. F., Lancelotta, R., Uthaug, M. V., Ramaekers, J. G., \& Davis, A. K. (2021). Naturalistic use of mescaline is associated with self-reported psychiatric improvements and enduring positive life changes. ACS Pharmacology \& Translational Science, 4(2), 543-552. https://doi.org/10.1021/acsptsci. $1 \mathrm{c} 00018$.
Aluoja, A., Shlik, J., Vasar, V., Luuk, K., \& Leinsalu, M. (1999). Development and psychometric properties of the Emotional State Questionnaire, a self-report questionnaire for depression and anxiety. Nordic Journal of Psychiatry, 53(6), 443-449. https://doi.org/10.1080/080394899427692.

Bagby, R. M., Parker, J. D., \& Taylor, G. J. (1994). The twenty-item Toronto Alexithymia Scale-I. Item selection and cross-validation of the factor structure. Journal of Psychosomatic Research, 38(1), 23-32. https://doi.org/10.1016/0022-3999(94)90005-1.

Barrett, F. S., Johnson, M. W., \& Griffiths, R. R. (2015). Validation of the revised Mystical Experience Questionnaire in experimental sessions with psilocybin. Journal of Psychopharmacology (Oxford, England), 29(11), 1182-1190. https://doi.org/10.1177/ 0269881115609019.

Bogenschutz, M. P., Forcehimes, A. A., Pommy, J. A., Wilcox, C. E., Barbosa, P. C. R., \& Strassman, R. J. (2015). Psilocybin-assisted treatment for alcohol dependence: A proof-of-concept study. Journal of Psychopharmacology (Oxford, England), 29(3), 289299. http://dx.doi.org.libproxy.albany.edu/10.1177/ 0269881114565144.

Bougie, R., Pieters, R., \& Zeelenberg, M. (2003). Angry customers don't come back, they get back: The experience and behavioral implications of anger and dissatisfaction in services. Journal of the Academy of Marketing Science, 31(4), 377-393.

Burk, R., Chappell, A., Gregory, M., Joslyn, C., \& McGrath, L. (2012). Pattern discovery using semantic network analysis. In 20123 rd international workshop on cognitive information processing (CIP) (pp. 1-6). IEEE.

Carhart-Harris, R. L., Bolstridge, M., Day, C., Rucker, J., Watts, R., Erritzoe, D. E., Kaelen, M., Giribaldi, B., Bloomfield, M., Pilling, S., Rickard, J. A., Forbes, B., Feilding, A., Taylor, D., Curran, H. V. \& Nutt, D. J. (2018). Psilocybin with psychological support for treatment-resistant depression: six-month follow-up. Psychopharmacology, 235(2), 399-408. https://doi.org/10.1007/ s00213-017-4771-x.

Carhart-Harris, R. L., Erritzoe, D., Haijen, E., Kaelen, M., \& Watts, R. (2018). Psychedelics and connectedness. Psychopharmacology, 235(2), 547-550.

Carhart-Harris, R., Giribaldi, B., Watts, R., Baker-Jones, M., MurphyBeiner, A., Murphy, R., Martell, J., Blemings, A., Erritzoe, D., \& Nutt, D. J. (2021). Trial of psilocybin versus Escitalopram for depression. New England Journal of Medicine, 384(15), 1402-1411.

da Costa Fernandes, S., Pigosso, D. C., McAloone, T. C., \& Rozenfeld, H. (2020). Towards product-service system oriented to circular economy: A systematic review of value proposition design approaches. Journal of Cleaner Production, 257, 120507.

Davis, A. K., Barrett, F. S., May, D. G., Cosimano, M. P., Sepeda, N. D., Johnson, M. W., Finan, P. H., \& Griffiths, R. R. (2021). Effects of psilocybin-assisted therapy on major depressive disorder: A randomized clinical trial. JAMA Psychiatry, 78(5), 481-489. https://doi.org/10.1001/jamapsychiatry.2020.3285.

Davis, A. K., Barrett, F. S., So, S., Gukasyan, N., Swift, T. C., \& Griffiths, R. R. (2021). Development of the Psychological Insight Questionnaire among a sample of people who have consumed psilocybin or LSD. Journal of Psychopharmacology, 35(4), 437-446.

Dittrich A. (1998). The standardized psychometric assessment of altered states of consciousness (ASCs) in humans. 
Pharmacopsychiatry, 31(Suppl 2), 80-84. https://doi.org/10. 1055/s-2007-979351.

Earleywine, M., Ueno, L. F., Mian, M. N., \& Altman, B. R. (2021). Cannabis-induced oceanic boundlessness. Journal of Psychopharmacology, 35(7), 841-847. https://doi.org/10.1177/ 0269881121997099.

Forstmann, M., Yudkin, D. A., Prosser, A. M., Heller, S. M., \& Crockett, M. J. (2020). Transformative experience and social connectedness mediate the mood-enhancing effects of psychedelic use in naturalistic settings. Proceedings of the National Academy of Sciences, 117(5), 2338-2346.

Fuller, J. A., Stanton, J. M., Fisher, G. G., Spitzmüller, C., Russell, S. S., \& Smith, P. C. (2003). A lengthy look at the daily grind: Time series analysis of events, mood, stress, and satisfaction. Journal of Applied Psychology, 88(6), 1019.

Gandy, S. (2019). Psychedelics and potential benefits in "healthy normals": A review of the literature. Journal of Psychedelic Studies, 3(3), 280-287.

Garcia-Romeu, A., Griffiths, R. R., \& Johnson, M. W. (2014). Psilocybin-occasioned mystical experiences in the treatment of tobacco addiction. Current Drug Abuse Reviews, 7(3), 157-164.

Gehlbach, H., \& Artino, A. R. (2018). The survey checklist (manifesto). Academic Medicine, 93(3), 360-366.

Gilbert, C. S., Earleywine, M., Mian, M. N., \& Altman, B. R. (2021). Symptom specificity of ayahuasca's effect on depressive symptoms. Journal of Psychedelic Studies, 5(1), 37-43.

Girn, M., Mills, C., Roseman, L., Carhart-Harris, R. L., \& Christoff, K. (2020). Updating the dynamic framework of thought: Creativity and psychedelics. Neuroimage, 213, 116726.

Griffiths, R. R., Johnson, M. W., Carducci, M. A., Umbricht, A., Richards, W. A., Richards, B. D., Cosimano, M. P., \& Klinedinst, M. A. (2016). Psilocybin produces substantial and sustained decreases in depression and anxiety in patients with lifethreatening cancer: A randomized double-blind trial. Journal of Psychopharmacology, 30(12), 1181-1197.

Griffiths, R. R., Johnson, M. W., Richards, W. A., Richards, B. D., Jesse, R., MacLean, K. A., Barrett, F. S., Cosimano, M. P., \& Klinedinst, M. A. (2018). Psilocybin-occasioned mystical-type experience in combination with meditation and other spiritual practices produces enduring positive changes in psychological functioning and in trait measures of prosocial attitudes and behaviors. Journal of Psychopharmacology, 32(1), 49-69. https://doi. org/10.1177/0269881117731279.

Griffiths, R. R., Johnson, M. W., Richards, W. A., Richards, B. D., McCann, U., \& Jesse, R. (2011). Psilocybin occasioned mysticaltype experiences: Immediate and persisting dose-related effects. Psychopharmacology, 218(4), 649-665.

Griffiths, R. R., Richards, W. A., McCann, U., \& Jesse, R. (2006). Psilocybin can occasion mystical-type experiences having substantial and sustained personal meaning and spiritual significance. Psychopharmacology, 187(3), 268-292. https://doi.org/ 10.1007/s00213-006-0457-5.

Haijen, E., Kaelen, M., Roseman, L., Timmermann, C., Kettner, H., Russ, S., Nutt, D., Daws, R. E., Hampshire, A., Lorenz, R., \& Carhart-Harris, R. L. (2018). Predicting responses to psychedelics: A prospective study. Frontiers in Pharmacology, 9, 897. https://doi.org/10.3389/fphar.2018.00897.
Hendricks, P. S. (2018). Awe: A putative mechanism underlying the effects of classic psychedelic-assisted psychotherapy. International Review of Psychiatry (Abingdon, England), 30(4), 331342. https://doi.org/10.1080/09540261.2018.1474185.

Jo, M. S. (2007). Should a quality sub-brand be located before or after the parent brand? An application of composite concept theory. Journal of the Academy of Marketing Science, 35 (2), 184-196.

Kettner, H., Gandy, S., Haijen, E. C., \& Carhart-Harris, R. L. (2019). From egoism to ecoism: Psychedelics increase nature relatedness in a state-mediated and context-dependent manner. International Journal of Environmental Research and Public Health, 16(24), 5147.

Kyhnau, J., \& Nielsen, C. (2015). Value Proposition Design: How to create products and services customers want. Journal of Business Models, 3(1).

Li, Y., Kenett, Y. N., Hu, W., \& Beaty, R. E. (2021). Flexible semantic network structure supports the production of creative metaphor. Creativity Research Journal, 1-15.

Luoma, J. B., Chwyl, C., Bathje, G. J., Davis, A. K., \& Lancelotta, R. (2020). A meta-analysis of placebo-controlled trials of psychedelic-assisted therapy. Journal of Psychoactive Drugs, 52(4), 289-299.

MacCallum, R. C., Widaman, K. F., Zhang, S., \& Hong, S. (1999). Sample size in factor analysis. Psychological Methods, 4(1), 84.

Machleit, K. A., Allen, C. T., \& Madden, T. J. (1993). The mature brand and brand interest: An alternative consequence of adevoked affect. Journal of Marketing, 57(4), 72-82.

MacLean, K. A., Leoutsakos, J. M. S., Johnson, M. W., \& Griffiths, R. R. (2012). Factor analysis of the mystical experience questionnaire: A study of experiences occasioned by the hallucinogen psilocybin. Journal for the Scientific Study of Religion, 51(4), 721-737.

Marchesi, C., Brusamonti, E., \& Maggini, C. (2000). Are alexithymia, depression, and anxiety distinct constructs in affective disorders? Journal of Psychosomatic Research, 49(1), 43-49.

Mason, N. L., Kuypers, K. P. C., Reckweg, J. T., Muller, F., Tse, D. H. Y., Da Rios, B., Toennes, S. W., Stiers, P., Feilding, A., \& Ramaekers, J. G. (2021). Spontaneous and deliberate creative cognition during and after psilocybin exposure. Translational Psychiatry, 11(1), 209. https://doi.org/10.1038/s41398-02101335-5.

Muttoni, S., Ardissino, M., \& John, C. (2019). Classical psychedelics for the treatment of depression and anxiety: A systematic review. Journal of Affective Disorders, 258, 11-24.

Nasel, D. D., \& Haynes, W. (2005). Spiritual and religious dimensions scale: Development and psychometric analysis. Australian Journal of Psychology, 57(1), 61-71.

Niemeier, J., Kennedy, R., McKinley, W., \& Cifu, D. (2004). The loss inventory: Preliminary reliability and validity data for a new measure of emotional and cognitive responses to disability. Disability and Rehabilitation, 26(10), 614-623.

Noorani, T., Garcia-Romeu, A., Swift, T. C., Griffiths, R. R., \& Johnson, M. W. (2018). Psychedelic therapy for smoking cessation: Qualitative analysis of participant accounts. Journal of Psychopharmacology, 32(7), 756-769. 
Nour, M. M., Evans, L., \& Carhart-Harris, R. L. (2017). Psychedelics, personality and political perspectives. Journal of Psychoactive Drugs, 49(3), 182-191.

Nour, M. M., Evans, L., Nutt, D., \& Carhart-Harris, R. L. (2016). Ego-dissolution and psychedelics: Validation of the ego-dissolution inventory (EDI). Frontiers in Human Neuroscience, 10, 269.

Pahnke, W. N. (1966). Drugs and mysticism. International Journal of Parapsychology, 8(2), 295-314.

Pahnke, W. N. (1969). Psychedelic drugs and mystical experience. International Psychiatry Clinics, 5(4), 149-162.

Quillian, R. (1963). A notation for representing conceptual information: An application to semantics and mechanical English paraphrasing. Systems Development Corporation.

Raju, S., Unnava, H. R., \& Montgomery, N. V. (2009). The moderating effect of brand commitment on the evaluation of competitive brands. Journal of Advertising, 38(2), 21-36.

Reynolds, K. E., Folse, J. A. G., \& Jones, M. A. (2006). Search regret: Antecedents and consequences. Journal of Retailing, 82(4), 339-348.

Reynolds, W. M., \& Kobak, K. A. (1995). Reliability and validity of the Hamilton depression inventory: A paper-and-pencil version of the Hamilton depression rating scale clinical interview. Psychological Assessment, 7(4), 472-483. https://doi.org/10. 1037/1040-3590.7.4.472.

Richards, W. A., Rhead, J. C., Dileo, F. B., Yensen, R., \& Kurland, A. A. (1977). The peak experience variable in DPT-assisted psychotherapy with cancer patients. Journal of Psychedelic Drugs, 9(1), 1-10.

Rifkin, B. D., Maraver, M. J., \& Colzato, L. S. (2020). Microdosing psychedelics as cognitive and emotional enhancers. Psychology of Consciousness: Theory, Research, and Practice, 7(3), 316-329. https://doi.org/10.1037/cns0000213.

Roberts, T. B. (2013). The psychedelic future of the mind: How entheogens are enhancing cognition, boosting intelligence, and raising values. Simon and Schuster.

Rochester, J., Vallely, A., Grof, P., Williams, M. T., Chang, H., \& Caldwell, K. (2021). Entheogens and psychedelics in Canada: Proposal for a new paradigm. Canadian Psychology/Psychologie canadienne.

Roseman, L., Haijen, E., Idialu-Ikato, K., Kaelen, M., Watts, R., \& Carhart-Harris, R. (2019). Emotional breakthrough and psychedelics: Validation of the emotional breakthrough inventory. Journal of Psychopharmacology, 33(9), 1076-1087.

Roseman, L., Nutt, D. J., \& Carhart-Harris, R. L. (2018). Quality of acute psychedelic experience predicts therapeutic efficacy of psilocybin for treatment-resistant depression. Frontiers in Pharmacology, 8, 974. https://doi.org/10.3389/fphar.2017.00974.

Rosenbusch, H., Wanders, F., \& Pit, I. L. (2020). The Semantic Scale Network: An online tool to detect semantic overlap of psychological scales and prevent scale redundancies. Psychological Methods, 25(3), 380.

Sarikhani, S. (2019). Are we walking in shoes too small? An enquiry into how psychedelic experiences relate to Kierkegaard's analyses of the self and despair, and their relevance to existential psychotherapy. Existential Analysis: Journal of the Society for Existential Analysis, 30(2).

Sarris, J., Perkins, D., Cribb, L., Schubert, V., Opaleye, E., Bouso, J. C., Scheidegger, M., Aicher, H., Simonová, H., Horák, M., Galvão-Coelho, N., Castle, D., \& Tófoli, L. F. (2021). Ayahuasca use and reported effects on depression and anxiety symptoms: An international cross-sectional study of 11,912 consumers. Journal of Affective Disorders, 4, 100098.

Schenberg, E. E., Tofoli, L. F., Rezinovsky, D., \& Silveira, D. X. D. (2017). Translation and cultural adaptation of the states of consciousness questionnaire (SOCQ) and statistical validation of the mystical experience questionnaire (MEQ30) in Brazilian Portuguese. Archives of Clinical Psychiatry (São Paulo), 44(1), $1-5$.

Schönbrodt, F. D., \& Perugini, M. (2013). At what sample size do correlations stabilize? Journal of Research in Personality, 47(5), 609-612.

Schouten, J. W., McAlexander, J. H., \& Koenig, H. F. (2007). Transcendent customer experience and brand community. Journal of the Academy of Marketing Science, 35(3), 357-368.

Simpson, G. M., Hackett, E., \& Kline, N. S. (1966). Difficulties in systematic rating of depression during out-patient drug treatment. Canadian Psychiatric Association Journal, Special Supplement, 11, S116-S121.

Smigielski, L., Kometer, M., Scheidegger, M., Krähenmann, R., Huber, T., \& Vollenweider, F. X. (2019). Characterization and prediction of acute and sustained response to psychedelic psilocybin in a mindfulness group retreat. Scientific Reports, 9(1), 14914. https://doi.org/10.1038/s41598-019-50612-3.

Stace, W. T. (1960). Mysticism and philosophy. New York: MacMillan Press.

Strassman, R. J., Qualls, C. R., Uhlenhuth, E. H., \& Kellner, R. (1994). Dose-response study of N,N-dimethyltryptamine in humans. II. Subjective effects and preliminary results of a new rating scale. Archives of General Psychiatry, 51(2), 98-108. https://doi.org/10.1001/archpsyc.1994.03950020022002.

Thrash, T. M., \& Elliot, A. J. (2003). Inspiration as a psychological construct. Journal of Personality and Social Psychology, 84, 871-889.

Winterich, K. P., Mittal, V., \& Ross, Jr, W. T. (2009). Donation behavior toward in-groups and out-groups: The role of gender and moral identity. Journal of Consumer Research, 36(2), 199-214.

Yaden, D. B., Kaufman, S. B., Hyde, E., Chirico, A., Gaggioli, A., Zhang, J. W., \& Keltner, D. (2019). The development of the awe experience scale (AWE-S): A multifactorial measure for a complex emotion. The Journal of Positive Psychology, 14(4), 474-488.

van der Zee, K. I., Bakker, A. B., \& Bakker, P. (2002). Why are structured interviews so rarely used in personnel selection? The Journal of Applied Psychology, 87(1), 176-184. https://doi.org/ 10.1037/0021-9010.87.1.176.

\footnotetext{
Open Access. This is an open-access article distributed under the terms of the Creative Commons Attribution-NonCommercial 4.0 International License (https:// creativecommons.org/licenses/by-nc/4.0/), which permits unrestricted use, distribution, and reproduction in any medium for non-commercial purposes, provided the original author and source are credited, a link to the CC License is provided, and changes - if any - are indicated.
} 